\title{
A low velocity zone beneath the Hida Mountains derived from dense array observation and tomographic method
}

\author{
Makoto Matsubara ${ }^{1}$, Naoshi Hirata ${ }^{1}$, Shin'ichi Sakai ${ }^{1}$, and Ichiro Kawasaki ${ }^{2}$ \\ ${ }^{1}$ The Earthquake Research Institute, the University of Tokyo, 1-1-1 Yayoi, Bunkyo-ku, Tokyo 113-0032, Japan \\ ${ }^{2}$ Toyama University, 3190 Gofuku, Toyama 930-8555, Japan
}

(Received April 23, 1999; Revised December 18, 1999; Accepted December 18, 1999)

\begin{abstract}
Seismic waves suffer strong attenuation when propagating beneath the Hida Mountains in Central Honshu, Japan. In order to study this region in detail, we conducted three kinds of dense seismic array observations in and around the Hida Mountains in the summer of 1996. Picking $P$ - and $S$-wave arrival time data from 54 events at 101 stations, 3175 $P$ - and $2335 S$-wave arrival time data were obtained for our tomographic study. Hypocenter locations and velocity structure were determined simultaneously. We assessed ray coverage and resolution of the velocity structure with checkerboard resolution tests. Ray paths for the model of the obtained velocity structure were examined in detail. There are two zones of low $P$-wave velocity, one at a depth of $4 \mathrm{~km}$ and the other at $15 \mathrm{~km}$. The resolution is good at depths of 0-20 km for $P$-wave velocities and at depths of $0-15 \mathrm{~km}$ for $S$-wave velocities. A high $V_{P} / V_{S}$ ratio (2.7) indicates that a partially melting rock exists beneath the Hida Mountains. The deep low velocity zone is located just above the upper/lower crustal boundary. These observations indicate that a magma reservoir exists in the upper crust beneath the Hida Mountains.
\end{abstract}

\section{Introduction}

Seismic waves suffer strong attenuation when propagating the crust beneath high mountains formed by uplift, such as the Himalayan Belt (Ruzaikin et al., 1977) and the Alpine Range (Campillo et al., 1993). The same thing was observed for the Japan Alps in Central Honshu (e.g., Katsumata et al., 1995). The Hida mountain range is located in the northern Japan Alps. It is one of the highest mountain ranges in Japan, located at the junction of the northeastern Japan arc and the southwestern Japan arc. The Hida mountain range is about $150 \mathrm{~km}$ long and oriented in the NEN-SWS direction. This region is also characterized by a number of conjugate sets of Quaternary active faults.

Ikeda (1996) pointed out that the uplift of the Hida Mountains started in the Miocene and that it had already grown into high mountains with large undulations by the end of the Miocene. Fukao and Yamaoka (1983) suggested that the Hida Mountains were uplifted by horizontal compressions of plate tectonic origin. Ikeda (1996), however, claimed that in the Quaternary, tensile stress was dominant in this region and that the intrusion of magmas thickened the region, as evidenced by the development of monogenic volcanoes.

Katsumata et al. (1995) revealed a strong low- $Q$ anomaly at depths of 5-15 km beneath the southern part of the Hida Mountains and an anomalously low velocity $(V)$ zone existing at a depth of $4 \mathrm{~km}$ beneath these mountains. The low$V /$ low- $Q$ zone has a shape of a convex lens with a thickness of $2 \mathrm{~km}$ at its center.

Mikumo et al. (1995) found that the axial part of the Hida

Copy right (C) The Society of Geomagnetism and Earth, Planetary and Space Sciences (SGEPSS); The Seismological Society of Japan; The Volcanological Society of Japan; The Geodetic Society of Japan; The Japanese Society for Planetary Sciences.
Mountains and its southwestward adjacent areas were generally covered with low $P$-wave velocities of $5.6-5.8 \mathrm{~km} / \mathrm{s}$ and that the low velocities might be associated with high temperature due to the active volcanism beneath these mountains. Some active volcanoes, such as Mts. Tatetama, Yake, Norikura, and Ontake, exist in that region.

The Research Group for Explosion Seismology (1994) conducted a seismic refraction experiment in central Japan and found that seismic waves passing through the Hida Mountains attenuated intensely. Sakai et al. (1996) analyzed the data from the experiment and found that the upper boundary of the anomalous body exists in convex form at depths of about $4-6 \mathrm{~km}$ as a reflector and that the low velocity zone is shallower than $20 \mathrm{~km}$ depth.

All these previous studies showed a low- $V /$ low- $Q$ zone existed beneath the Hida Mountains. However, none of them clarified the detailed structure of the anomalous body. The detailed structure of the anomaly is important for our understanding of the formation of the Hida mountain range. The purpose of the present study is to examine the region in great detail, i.e., where the low velocity zone is located, how large it is, and how slow the $P$ - and $S$-wave velocities ( $V_{P}$ and $V_{S}$ ) are.

For these purposes we need to observe earthquakes using a dense seismic array with three-component seismometers. In 1996 a joint seismic observation was carried out in Chubu District by the Japanese University Group for Earthquake Prediction Research (GROUPS96, 1996).

\section{Seismic Array Experiments}

We deployed three seismic arrays: (1) Alpine Route Array (ARA), (2) Remote Mountain Area Array (RMA), and (3) 
Table 1. Seismometers used in the 1996 observation. ARA: Alpine route array. RMA: Remote mountain area array. TTA: Temporary Telemetered Array at Toyama University. All arrays are equipped with three-component seismometers.

\begin{tabular}{cccccc}
\hline Array & Geophone & $\begin{array}{c}\text { Natural frequency } \\
{[\mathrm{Hz}]}\end{array}$ & Mechanism & $\begin{array}{c}\text { Sensitivity } \\
{[\mathrm{Vm} / \mathrm{s}]}\end{array}$ & Stations \\
\hline ARA & L22D & 2 & passive & 56.5 & 44 \\
RMA & LE3D/5s & 0.2 & feedback & 400 & 3 \\
TTA & MTDH-1C & 1 & passive & $160-240$ & 8 \\
\hline
\end{tabular}

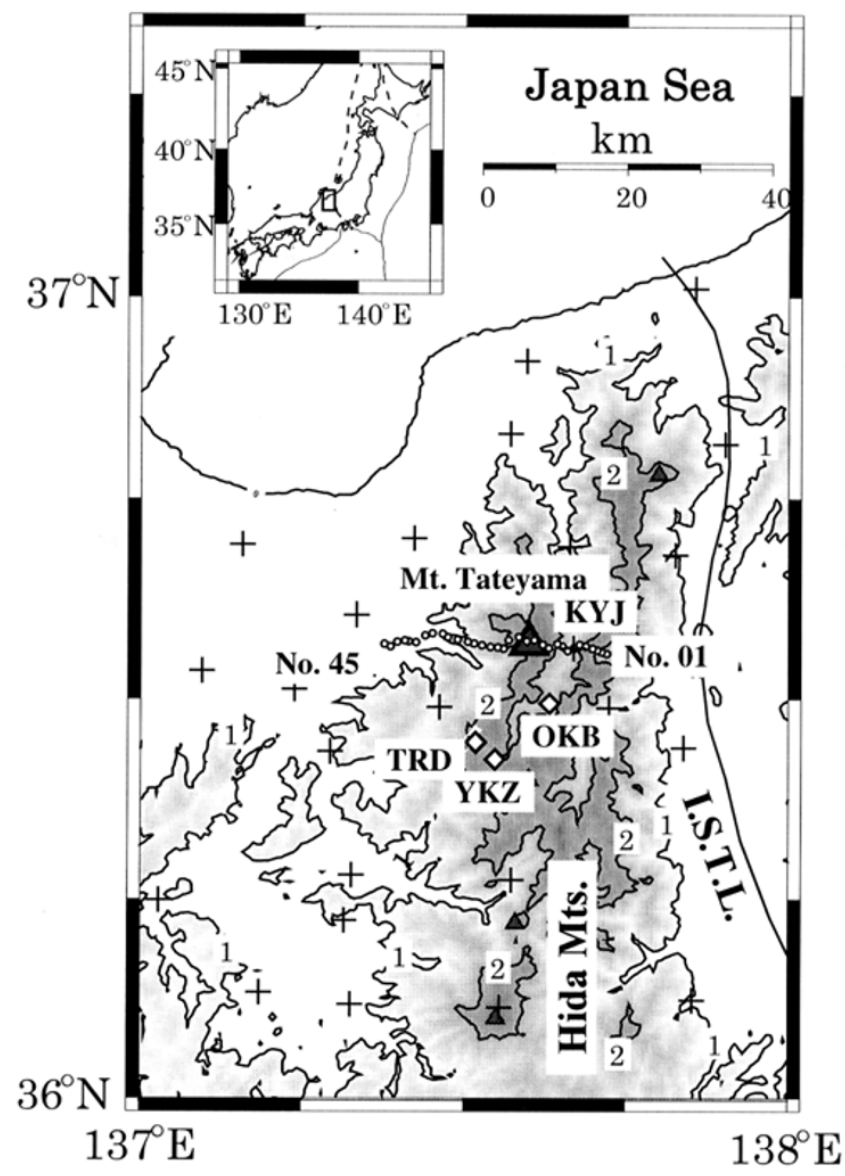

Fig. 1. Distribution of seismic arrays. Circle, diamond and plus symbols denote the ARA stations, the RMA stations, and the TTA and other telemetered stations, respectively. Triangle symbols denote volcanoes. Solid lines denote active faults. Numerals are height in $\mathrm{km}$. Names of the main districts and some stations are also shown. I.S.T.L. is Itoigawa-Shizuoka Tectonic Line, which is the giant fault dividing the northeastern Japan arc and the southwestern Japan arc.

Temporary Telemetered Array (TTA) (Fig. 1). In the present study, we mainly analyzed the ARA and RMA data, and also used the TTA data for locating events. The data from RMA are important for locating local microearthquakes. TTA data are necessary for locating the regional deep earthquakes. Table 1 shows details of the three array experiments.

We deployed 44 three-component portable seismographs in a linear array (ARA) from July 29 to October 2, 1996, along the Tateyama-Kurobe Alpine Route to observe natural earthquakes. We designed this array on the basis of the previous observations (Research Group for Explosion Seismology, 1994; Katsumata et al., 1995). The length of the array was about $45 \mathrm{~km}$ from station No. 01 at the eastern end of the profile to station No. 45 at the western end. No portable seismograph was deployed at the location that was supposed to be No. 19, because there we installed a temporary telemetered station (KYJ in the TTA).

Each seismograph system consisted of a $2-\mathrm{Hz}$, threecomponent seismometer and a long-term, low-power digital audio tape (DAT) recorder (Shinohara et al., 1997). The DAT recorder included a Global Positioning System (GPS) receiver, an amplifier, and dry batteries. The GPS receiver provided a precise clock signal for the timing of recording.

Waveforms were continuously recorded at a sampling rate of $100 \mathrm{~Hz}$ because very weak seismic signals, which were attenuated beneath the Hida Mountains, were difficult to be recorded by the event triggering method. The accuracy of time of the recorder is very important in evaluating the delays of travel time. Each recorder received a GPS signal every 6 hours and recorded the times of the recorder clock and the GPS clock to maintain the accuracy of the recording timing within $1 \mathrm{~ms}$.

Seismographs were installed with a spacing of about $1 \mathrm{~km}$ in order to detect the extent of the attenuation structure in detail. The dense distribution of stations in this study is one of its advantages over the previous work (e.g., Katsumata et al., 1995).

Three portable stations were deployed in a remote mountain area (RMA) from August 4 to September 18, 1996. These stations were located in the southern part of the Hida Mountains. The recording system of these three stations was the same as those of the ARA stations except for seismometers, which had a natural frequency of $0.2 \mathrm{~Hz}$.

We deployed eight temporary telemetered stations (TTA) from July 20 to October 20, 1996, around the ARA. Each seismograph system consisted of a $1-\mathrm{Hz}$, three-component seismometer, an amplifier, and a data transmitter using a telephone line. The TTA had an average station spacing of 15 $\mathrm{km}$. They were telemetered and recorded at Toyama University. The TTA was connected to the routine seismic network of the Earthquake Research Institute (ERI), the University of Tokyo, through the Internet link.

\section{Data}

The continuously recorded data from the ARA and RMA stations were processed in the laboratory after the observations. First they were divided into event data, each of which 


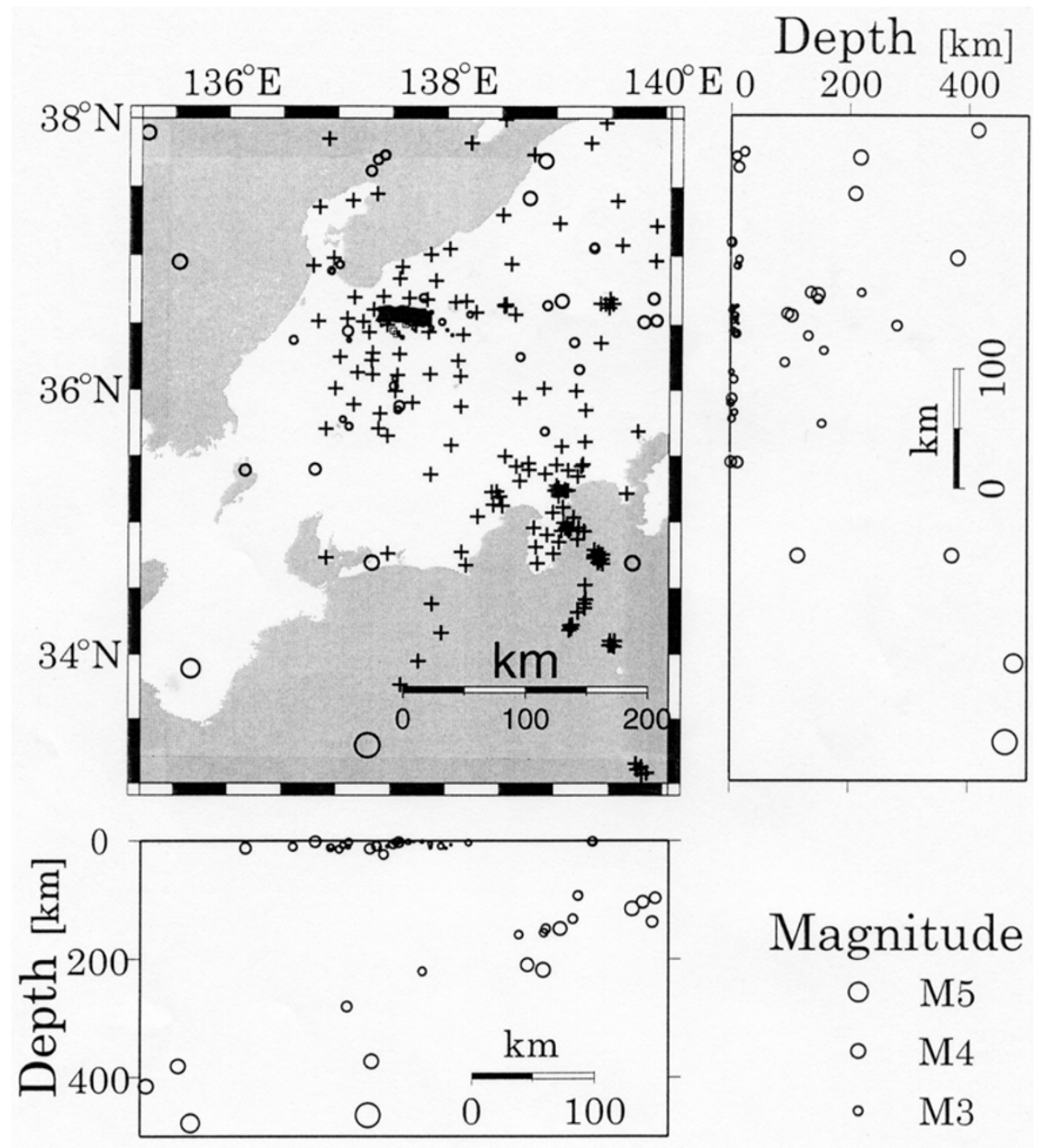

Fig. 2. Distribution of hypocenters used for travel time inversion. A thick line indicates the ARA stations. Circles, squares, and pluses denote hypocenters, the RMA stations, and the TTA and other telemetered stations, respectively.

had waveform data from an earthquake with time corrections. We used a win-format to pick arrival times, and this format was used in the ERI routine recording system (Urabe, 1994). We combined the ARA and RMA data with the data of the TTA and ERI seismic network. Data quality for all of the RMA stations was good and those for 37 of the 44 ARA stations were good. We used these combined data from the ARA, RMA, TTA, and ERI seismic network in this study.

During the ARA observation, the TTA stations and the ERI seismic network determined the hypocenters of 968 earthquakes in the latitude range of $29^{\circ}-44^{\circ} \mathrm{N}$, longitude range of $134^{\circ}-143^{\circ} \mathrm{E}$, and a depth range of $0-600 \mathrm{~km}$. We recognized 412 events among them from the records at more than half of the ARA stations.

We picked $P$ - and $S$-wave arrivals of 54 events at 101 stations (including the ARA, RMA, TTA, and ERI routine stations) and obtained $3175 P$ - and $2335 S$-wave arrival times, which were used in the inversion analysis. We tried to select the local crustal events which are distributed uniformly in the study area. However, there were more deep events to the east of the ARA than there were to the west. We used the

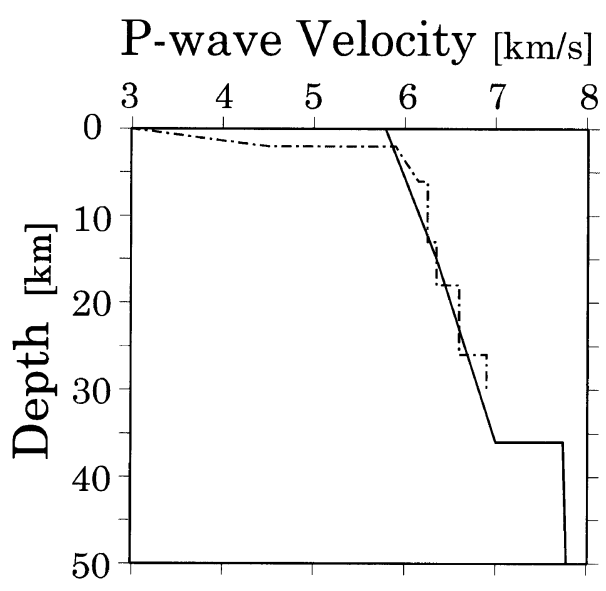

Fig. 3. Initial model of $V_{P}$. The solid line denotes the initial model of $V_{P}$ used in this study. The dashed line denotes $V_{P}$ derived from a seismic refraction method (Takeda, 1997). 


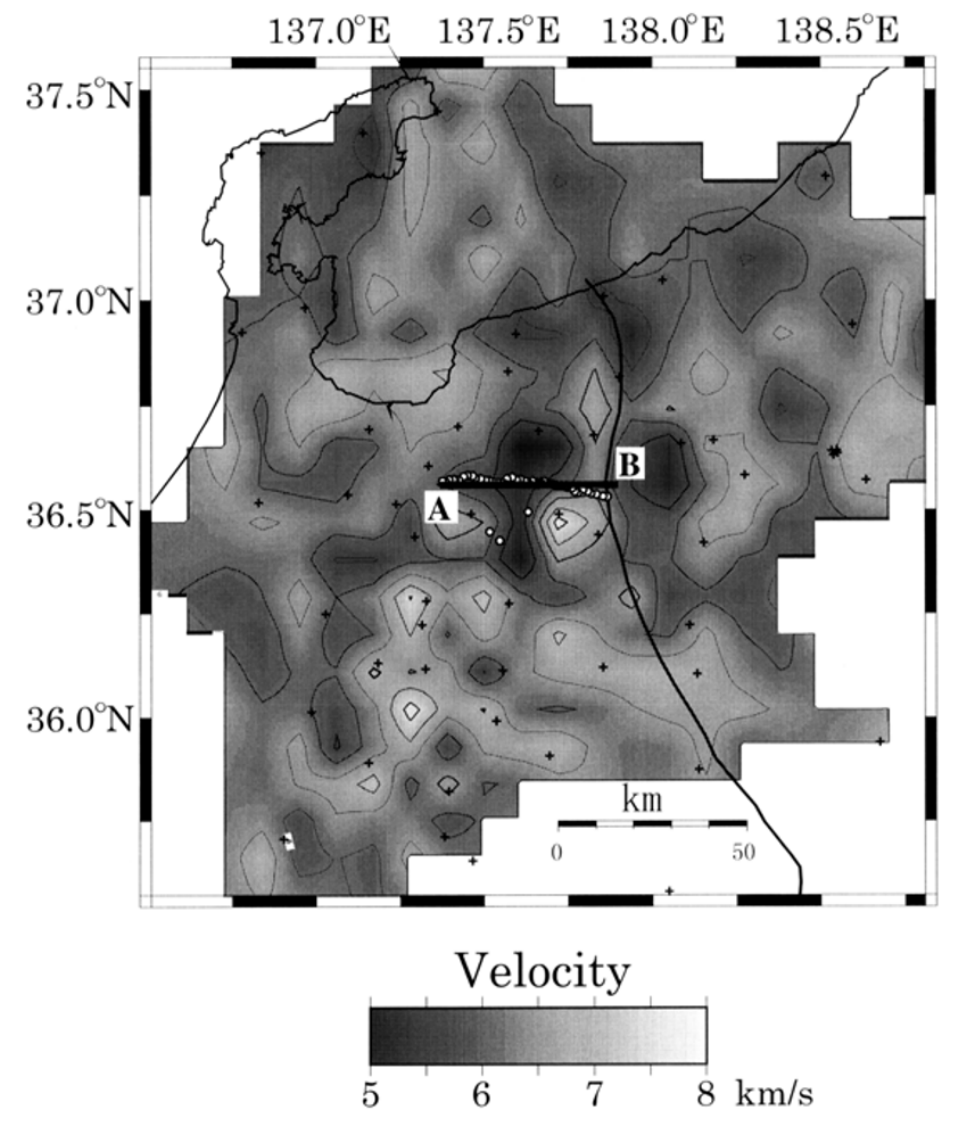

Fig. 4. $P$-wave velocity tomogram at a depth of $10 \mathrm{~km}$. $P$-wave velocities are indicated by gray scale in $\mathrm{km} / \mathrm{s}$. Solid black contour lines also indicate $V_{P}$ in $\mathrm{km} / \mathrm{s}$.

travel time data of waves propagating in the vertical direction from the deep events to resolve the east-west extent of the anomalous zone. Figure 2 shows the hypocentral distribution of 54 selected events, including: (a) 17 local events with epicentral distances (D) smaller than $30 \mathrm{~km}$ and magnitudes (M) greater than 1.0; (b) 18 shallow events with $\mathrm{D}<30 \mathrm{~km}$ and $M>2.0$; and (c) 19 deep events with $M>2.5$ from the original 412 events.

We determined the hypocenters of the 54 events with a program "hypomh" (Hirata and Matsu'ura, 1987). The velocity structure used for the determination of the initial hypocenters was a one-dimensional (1-D) layered velocity structure derived from a seismic refraction method (Takeda, 1997). $V_{P} / V_{S}$ ratio was assumed to be 1.73 .

\section{Travel Time Inversion}

We applied the tomographic method of Zhao et al. (1992) to our data set to determine three dimensional (3-D) velocity structure in the Hida region. A 3-D grid net is set up in the study area. Velocities at the grid nodes are taken as unknown parameters. First, we adopted a spacing of $10 \mathrm{~km}$ between the grid nodes in the latitudinal, longitudinal, and depth directions to estimate the rough velocity structure beneath the whole of Chubu District. Next, to investigate the region beneath the ARA in detail, we adopted a spacing of $5 \mathrm{~km}$ in the longitudinal direction from $137.315^{\circ} \mathrm{E}$ to $137.920^{\circ} \mathrm{E}$ because the average spacing of the ARA stations is about $1 \mathrm{~km}$. We also adopted a spacing of $5 \mathrm{~km}$ in the depth direction at depths of $0-30 \mathrm{~km}, 10 \mathrm{~km}$ at depths of $30-100 \mathrm{~km}$, and 50 $\mathrm{km}$ at depths of $100-400 \mathrm{~km}$.

As an initial model for the 3-D inversion, we adopted the 1$D$ velocity structure which was used for the initial hypocenter location. The $V_{P}$ of the model increased from $5.8 \mathrm{~km} / \mathrm{s}$ at the earth's surface to $6.35 \mathrm{~km} / \mathrm{s}$ at a depth of $15 \mathrm{~km}$ and 7.00 $\mathrm{km} / \mathrm{s}$ at a depth of $36 \mathrm{~km}$. Below a depth of $36 \mathrm{~km}$, we used the Jeffreys-Bullen model (Fig. 3).

Hypocentral parameters were redetermined five times per velocity iteration. The maximum changes of the origin times were restricted to $0.9 \mathrm{~s}$ per relocation iteration. We restricted the maximum change of location per iteration to be the distance in which the $P$-wave radiated from the hypocenter in 0.9 s (i.e., $\left(V_{P}\right.$ at the hypocenter $\left.) \times 0.9\right)$.

The inversion of only $P$-wave arrival time data was performed at first with a constant $V_{P} / V_{S}$ ratio (1.73). After obtaining a new $V_{P}$ structure, we performed an inversion of only $S$-wave data with the fixed new $V_{P}$. The number of data of $P$-wave was larger than that of $S$-wave, and $S$-wave arrival times might have larger errors than $P$-wave data because of the difficulty of picking the $S$-wave arrival times. If the inversion of $P$ - and $S$-wave data was performed simultaneously, the lower quality of the $S$-wave result may affect the next inversion of $P$-wave data.

We carried out a checkerboard resolution test to assess the adequacy of ray coverage and to evaluate the resolution (Zhao et al., 1992; Zhao and Hasegawa, 1993). We assigned positive or negative velocity perturbations of $\pm 10 \%$ to the 
A

B

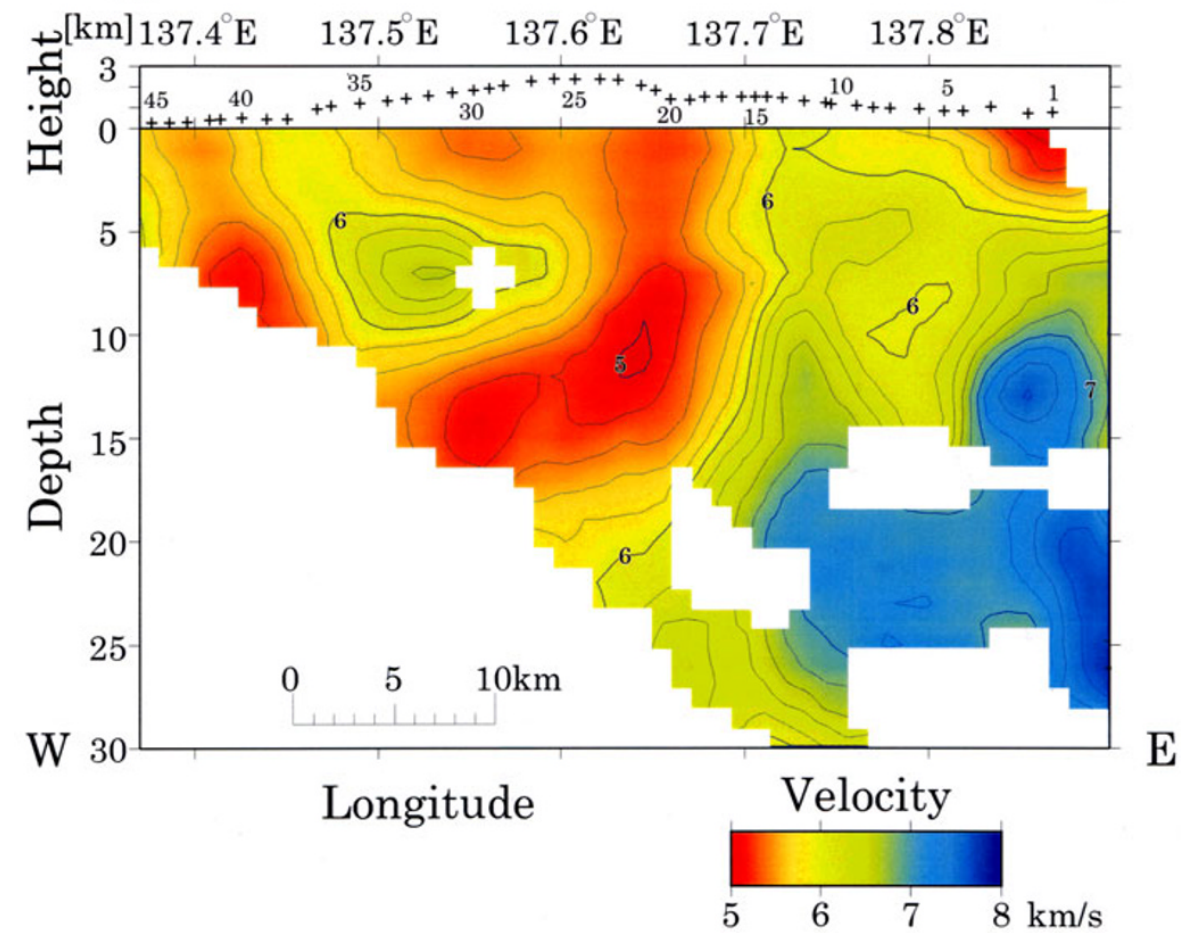

Fig. 5. E-W vertical cross-section of $V_{P}$ of weighted average of $255-\mathrm{km}$-spacing-grid tomograms. Areas with resolution ratio less than 0.15 are painted white. Solid contour lines indicate $V_{P}$ in $\mathrm{km} / \mathrm{s}$. The contour interval is $0.2 \mathrm{~km} / \mathrm{s}$. $P$-wave velocity is also indicated by color code in $\mathrm{km} / \mathrm{s}$. Positions of the ARA stations are indicated by plus symbols in the upper panel. Numerals in the upper panel are the station numbers.

A

B

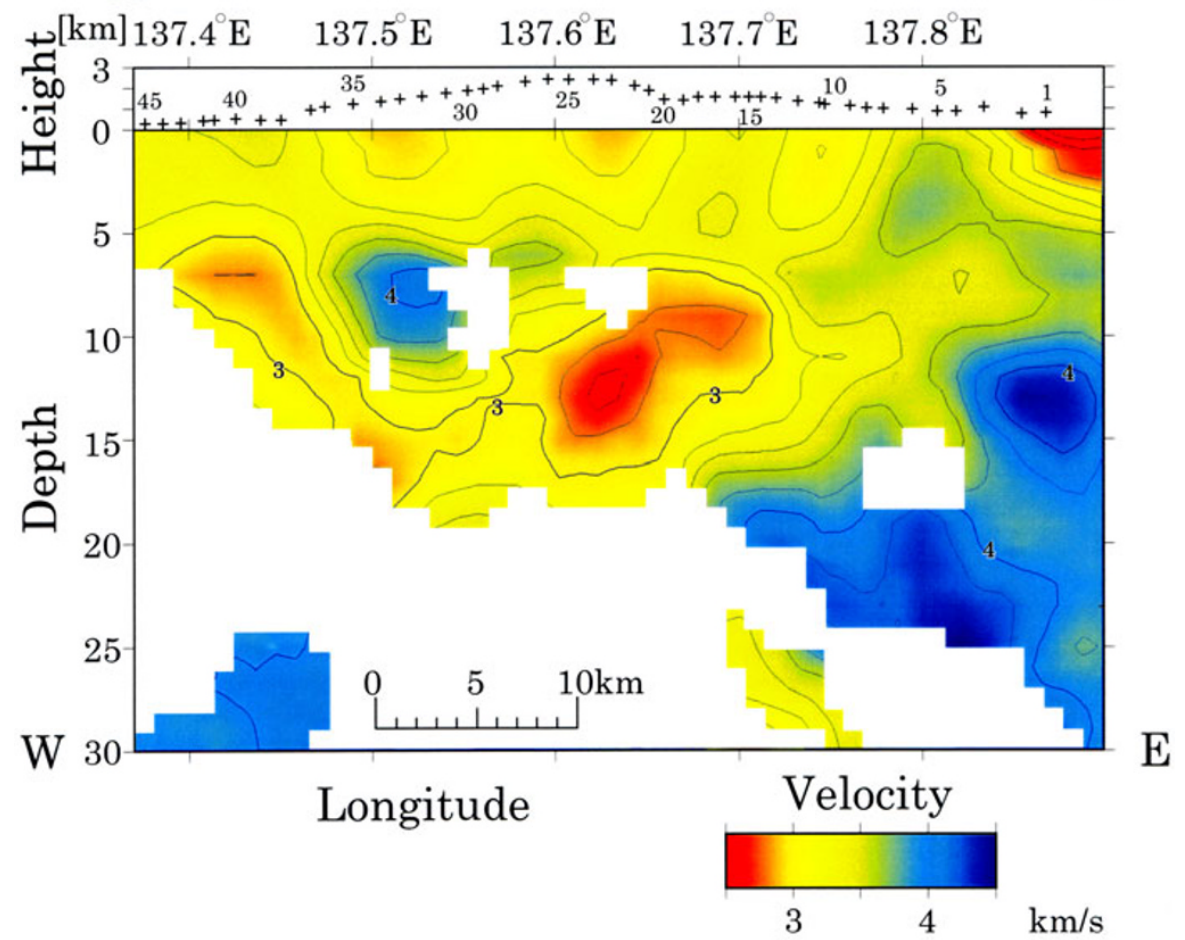

Fig. 6. E-W vertical cross-section of $V_{S}$ of weighted average of $255-\mathrm{km}$-spacing-grid tomograms. Areas with resolution ratio less than 0.15 are painted white. Solid contour lines indicate $V_{S}$ in $\mathrm{km} / \mathrm{s}$. A contour interval is $0.2 \mathrm{~km} / \mathrm{s}$. $S$-wave velocity is also indicated by color code in $\mathrm{km} / \mathrm{s}$. 
grid nodes because we estimated the average velocity perturbation from the inversion of real data to be about $10 \%$. We calculated the travel times for the checkerboard model to make synthetic data and inverted them with an initial model of zero velocity perturbations everywhere.

We used a 5-km-spacing grid for the inversion. The positions of grid nodes may influence the result. To remove this influence, 25 inversions with different grid node positions were performed. Twenty-five tomograms were averaged to get a smoothed velocity model. Checkerboard resolution tests were also performed on the 25 different grid node positions.

To smooth the velocity model, resolutions of the inversion should be taken into account. We used a "resolution ratio" to evaluate the reliability of solutions: the resolution ratio is defined as the ratio of the estimated perturbation to the assigned perturbation (10\%) at each grid in the checkerboard test. For example, if the assigned velocity perturbation is $10 \%$ and the inverted perturbation after the checkerboard test is $1 \%$, the resolution ratio is 0.1 .

The smoothed velocity at one grid node was the weighted sum of those at the node and its 24 surrounding grid nodes weighted by the resolution ratio.

$$
v_{s}=\frac{\sum_{i=1}^{25} v_{i} w_{s i} r_{i}}{\sum_{i=1}^{25} w_{s i} r_{i}}
$$

where $v_{s}$ was the smoothed velocity at the center grid node and $v_{i}$ was the velocity at the $i$-th grid node, $w_{s i}$ was the weight and $r_{i}$ was the resolution ratio of the $i$-th grid node. The weight of a grid node, $w_{s i}$, was in inverse proportion to the distance between the grid node and the center grid node. If the resolution ratio of a grid node was less than 0.15 , we considered that this grid node did not have a reliable solution and we reduced the weight of the grid node to zero. If 15 or more surrounding grid nodes had zero weight, the weight of the center grid node was reduced to zero.

\section{Results}

The result of $V_{P}$ structure at a depth of $10 \mathrm{~km}$ is shown in Fig. 4. It is one of the five horizontal slides. The $V_{P}$ at sea level is $15 \%$ lower in the Toyama plains and the Northern Fossa Magna than the average velocity. Beneath the Hida Mountains it is $10 \%$ lower. The $V_{P}$ at depths of 5 and 10 $\mathrm{km}$ beneath the Hida Mountains is $20 \%$ lower. At a depth of $15 \mathrm{~km}$ beneath the western part of the ARA, it is $20 \%$ lower. The $V_{P}$ at a depth of $20 \mathrm{~km}$ beneath the Hida Mountains is $5 \%$ lower than the average velocity.

Vertical cross-sections of the inverted $V_{P}$ and $V_{S}$ along line $\mathrm{AB}$ (Fig. 4) are shown in Figs. 5 and 6, respectively. The lowest $V_{P}, 4.92 \mathrm{~km} / \mathrm{s}$, is located at a depth of $11 \mathrm{~km}$ and at a longitude of $137.645^{\circ} \mathrm{E}$. The lowest $V_{S}, 2.54 \mathrm{~km} / \mathrm{s}$, is located at a depth of $13 \mathrm{~km}$ and at a longitude of $137.623^{\circ} \mathrm{E}$. $V_{P}$ and $V_{S}$ have a similar pattern.

The root-mean-square (RMS) travel time residual of $P$ wave is $0.5531 \mathrm{~s}$ before the inversion and is reduced to 0.3262 $\mathrm{s}$ after five iterations. That of $S$-wave is reduced from 0.6029 $\mathrm{s}$ to $0.4393 \mathrm{~s}$ after five iterations.
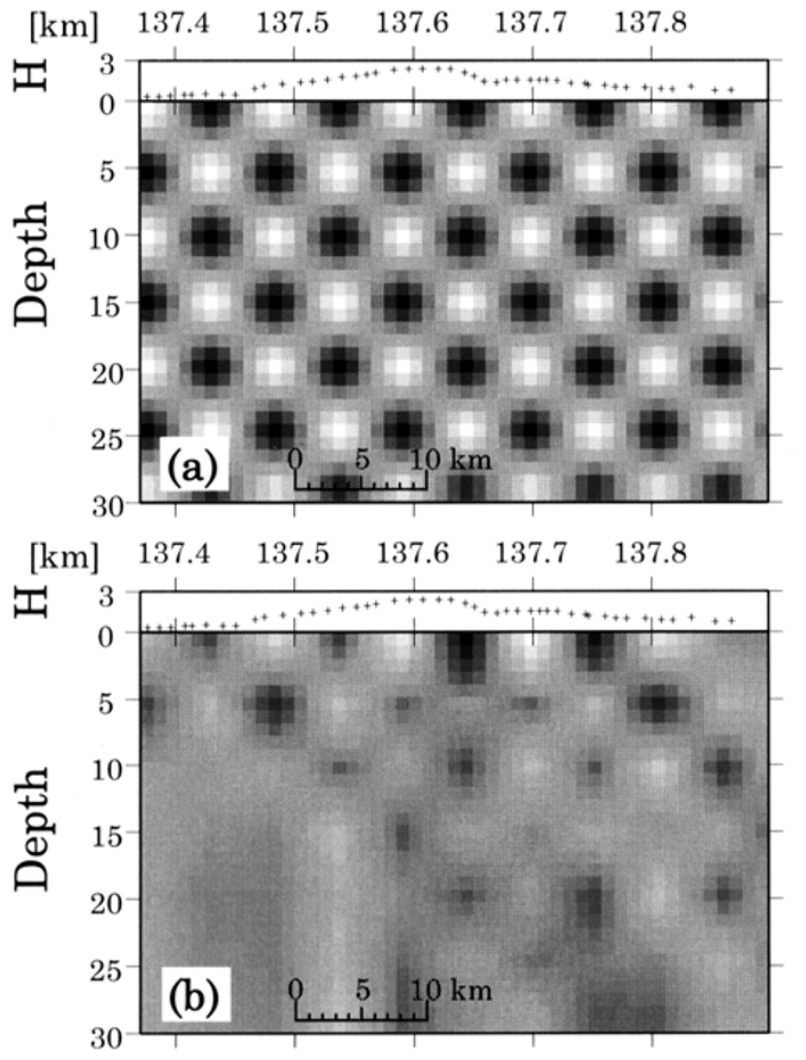

$\left[\begin{array}{llllll}{[\mathrm{km}]} & 137.4 & 137.5 & 137.6 & 137.7 & 137.8\end{array}\right.$

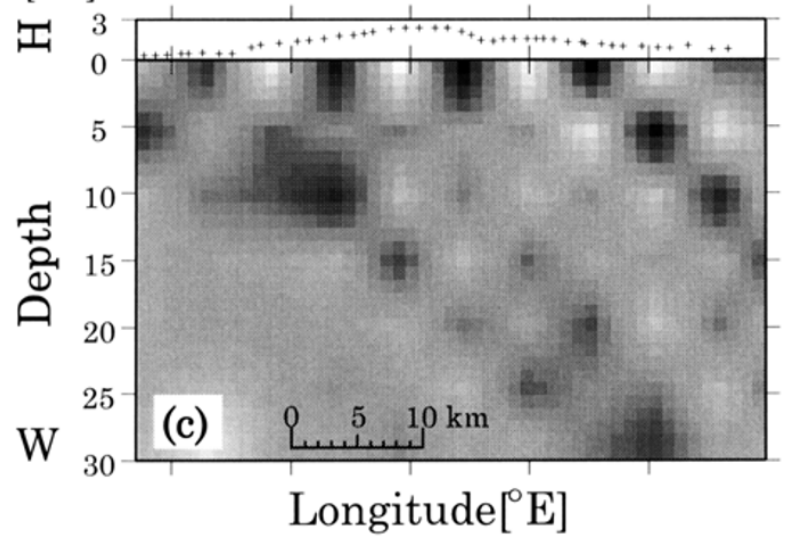

E

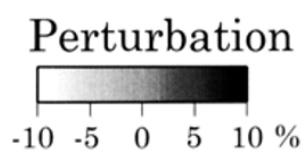

Fig. 7. Checkerboard resolution test on an E-W vertical cross-section (A-B in Fig. 4). The perturbations are indicated by gray scale in \%. (a) Assigned perturbation of $V_{P}$ and $V_{S}$. The maximum perturbation is $10 \%$. (b) One of the results of tests for $V_{P}$. (c) One of the results of tests for $V_{S}$.

\section{Discussion}

\subsection{Reliability of the model and error and resolution analysis}

Figure 7 shows the results of checkerboard tests. The resolution for both $V_{P}$ and $V_{S}$ is good under all stations in the depth range of $0-5 \mathrm{~km}$. At depths of 5-10 km, the resolution of the eastern and western parts of the ARA is good for both $V_{P}$ and $V_{S}$. The resolution of the central and eastern parts of 


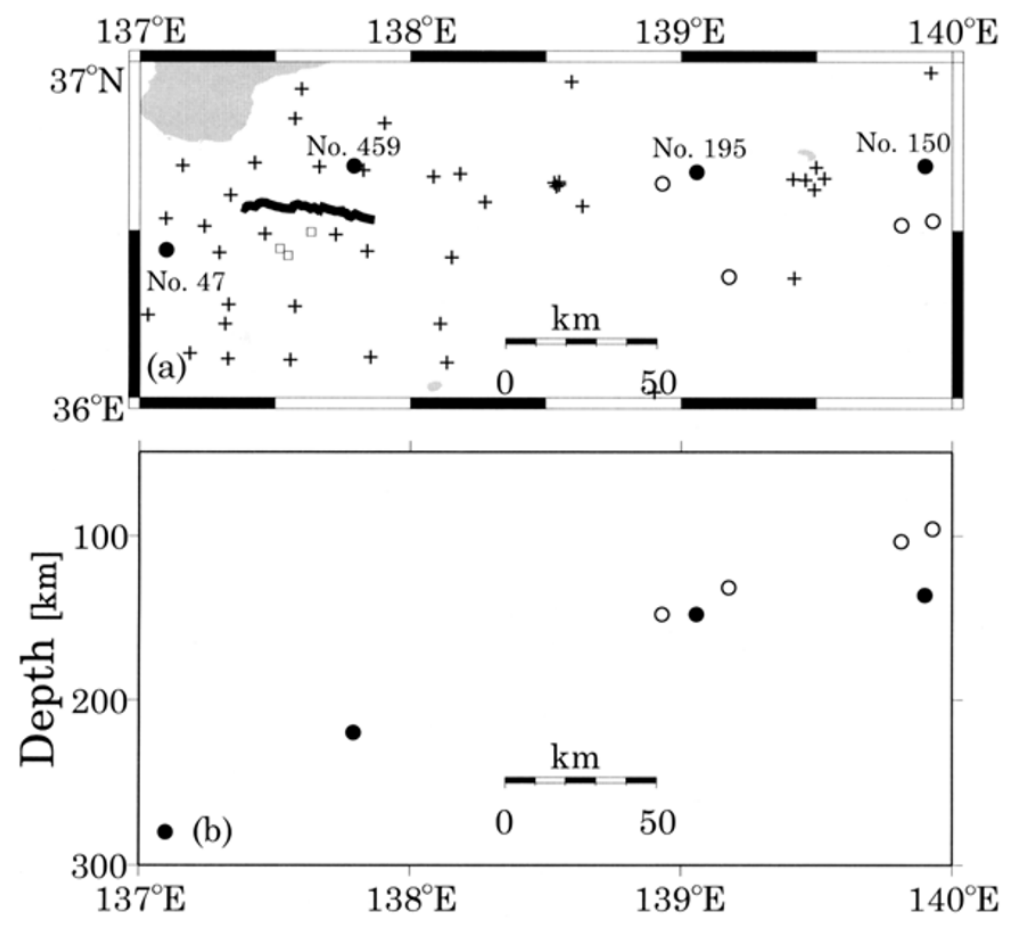

Fig. 8. Deep events used for forward modeling. Open circles in the upper plate denote epicentral locations of the events which occured from August to September $1996(\mathrm{M}>2.5)$. Solid circles in the lower plate denote hypocenters used for forward modeling. Open circles in the lower plate denote hypocenters determined in this study. A thick line indicates the ARA stations. Squares denote the RMA stations. Pluses denote the TTA and other telemetered stations. (a) Epicentral distribution. (b) Depth distribution.

the ARA is good in the depth range of $10-20 \mathrm{~km}$ for $V_{P}$ and at depths of $10-15 \mathrm{~km}$ for $V_{S}$.

The resolution is not good at a depth of $7 \mathrm{~km}$. This is because the number of arrival time data is relatively small, which, in turn, is because the rays bent so as not to pass through the low- $V$ zone also do not pass through the zone at a depth of $7 \mathrm{~km}$. The number of events occurring to the east of the ARA is larger than that of events occurring to the west. It is difficult to pick the $P$ - and $S$ - arrivals for the events occurring to the east because waves are attenuated when passing through the low velocity area.

The travel time inversion solves the high velocity area well, but not so well the low velocity area. This is partly due to the bending of ray paths in a heterogeneous medium. The ray paths are bent so that they do not pass the low velocity area. The low velocity area may therefore show a lower perturbation than the obtained one. In contrast, the high velocity area is considered to be solved well.

We examined the model resolution by other numerical experiments. We calculated synthetic travel times based on one structure of the 25 tomograms with a $5-\mathrm{km}$ grid spacing and inverted them to obtain a velocity model. At a depth of 5 $\mathrm{km}$ where the resolution is not good, the given velocity perturbation of the structure was $-14 \%$ and the obtaind velocity perturbation was $-6.7 \%$. The distribution of high or low velocity zone in the obtained model is similar to the given structure. We also gave a high or low velocity perturbation to one grid node of the model, calculated synthetic travel times, and inverted them (one-point anomaly test). The grid node is located at the area where a high or low velocity is estimated in real data. First, a high velocity perturbation
$(+10 \%)$ was given to a grid node at a depth of $5 \mathrm{~km}$ beneath station No. 31 (Case 1). Second, a low perturbation (-10\%) was given to a grid node at a depth of $10 \mathrm{~km}$ beneath station No. 21 (Case 2) or at a depth of $15 \mathrm{~km}$ beneath station No. 31 (Case 3). Table 2 summarizes results of the one-point anomaly tests.

The resolution analysis indicates that the low velocity zone spreads upward in the western side and lowers eastward. The high or low velocity perturbations given to the models are all $10 \%$. The result of the highest perturbation is $+6.9 \%$ (Case 1 ) among the grid nodes that we gave $+10 \%$ perturbation, and the result of the lowest perturbation is $-4.6 \%$ (Case 2 ) and $-4.2 \%$ (Case 3 ) among those we gave $-10 \%$ perturbation.

To evaluate errors in the estimated velocity structure, 100 synthetic data sets with random noise were generated from one of the tomograms with a $5-\mathrm{km}$ grid spacing and inverted them to obtain velocity models. We calculated an average and a standard deviation of 100 tomograms to evaluate errors propagated from the arrival time data to model parameters. We calculated synthetic travel time data based on the final velocity model. Then we added random numbers to the synthetic data with zero mean and a standard deviations of 0.05 $\mathrm{s}$ and $0.1 \mathrm{~s}$ for $P$ - and $S$-wave arrival times, respectively, according to the errors in the pickings of the $P$ - and $S$-wave arrivals.

The estimated $V_{P}$ within the low velocity area is $0.1 \mathrm{~km} / \mathrm{s}$ higher than that of assumed $V_{P}$ for the numerical experiment. The standard deviation of $V_{P}$ in the low velocity area is 0.02 $\mathrm{km} / \mathrm{s}$. 
Table 2. Result of the resolution analyses (one-point anomaly tests). In Cases 1 and 2, we gave an anomalous grid node below station No. 31 . In Case 3, we gave an anomalous grid node below station No. 21. In all cases, we located an anomalous grid node at $36.55^{\circ} \mathrm{N}$ on the same line as the E-W vertical cross-section (A-B in Fig. 4).

\begin{tabular}{|c|c|c|c|c|c|c|}
\hline \multirow[t]{3}{*}{ Case } & \multicolumn{2}{|c|}{ Location } & \multirow[t]{2}{*}{ Given* } & \multirow[t]{2}{*}{ Inverted $^{* *}$} & \multicolumn{2}{|c|}{ Range of $1.5 /-1.5 \% * * *$} \\
\hline & Longitude & Depth & & & Longitude & Depth \\
\hline & ${ }^{\circ} \mathrm{E}$ & $\mathrm{km}$ & $\%$ & $\%$ & ${ }^{\circ} \mathrm{E}$ & $\mathrm{km}$ \\
\hline 1 & 137.55 & 5 & 10 & 6.9 & $137.51-59$ & $1-9$ \\
\hline 2 & 137.55 & 10 & -10 & -4.6 & $137.50-58$ & $8-20$ \\
\hline 3 & 137.64 & 15 & -10 & -4.2 & $137.61-70$ & $5-15$ \\
\hline
\end{tabular}

\footnotetext{
* Given perturbation.

* Inverted perturbation.

** Range of area with a perturbation of more/less than $1.5 /-1.5 \%$.
}

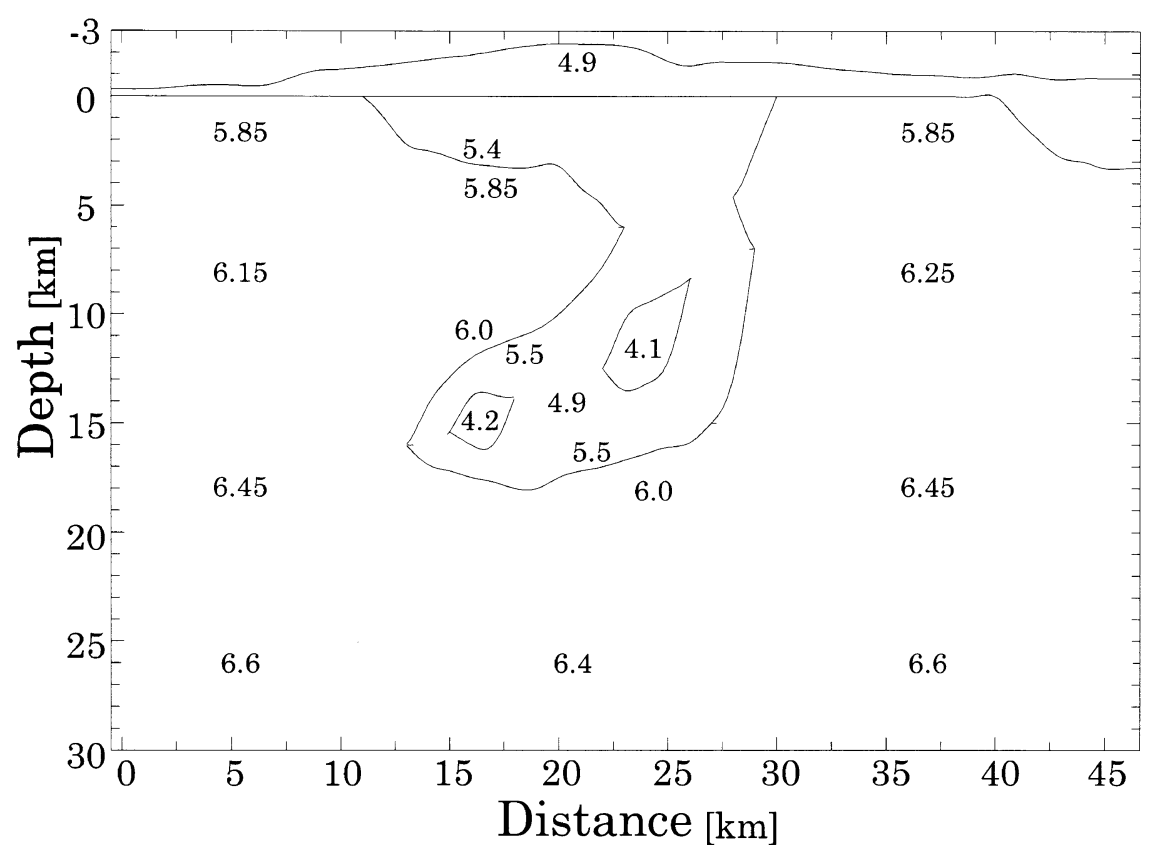

Fig. 9. Model of $V_{P}$ for forward calculation of rays. The model area is the same as in Fig. 6 . Numerals are $V_{P}$ in km/s. The horizontal axis is the distance from No. 45 to the east.

\subsection{Forward modeling}

In our tomographic inversion we used the travel times of first arrivals but did not consider the later phases. The obtained 3-D model is so complicated that it may generate later phases. The ray paths and travel times from deep events (Fig. 8) were calculated by using an asymptotic ray method (Červený and Psencik, 1983).

First, we made a model based on the $V_{P}$ tomogram. The model was simplified to simulate the ray paths and travel times of both the first and later phases (Fig. 9). We examined the ray paths for the inverted velocity model to see if the calculated travel times of the first arrivals coincide with the observed times. Then, we investigated if the structure would produce later phases which appear in the observed seismograms. If the later phases are not produced, we would gradually change the shape and the velocity of the model.

From the error analysis in Subsection 6.1, we consider that the low $V_{P}$ can be lower than the inverted velocity. We reduced the velocity in the low velocity zone to explain the travel times of the first and the later phases. We modeled the $V_{P}$ structure and then the $V_{S}$ structure.

An example of the synthetic seismogram for an event at a depth of $147.92 \mathrm{~km}$ is shown in Fig. 10. The ray passing through the low $V_{P}$ area bends sharply (Fig. 11). Calculated travel times of the first and the later phases explain the observed travel times well (Fig. 12).

From the results of forward modeling, the low $V_{P}$ is estimated to be $4.10 \mathrm{~km} / \mathrm{s}$ at a depth of $11 \mathrm{~km}$, and the low $V_{S}$ is $1.50 \mathrm{~km} / \mathrm{s}$ at the same place. The $V_{P} / V_{S}$ is 2.70 . These low velocities produce the later phases observed in the real data (Figs. 10 and 12).

From the tomogram with a 5-km grid spacing, we found the low $V_{P}$ zone beneath the ARA, but it is too rough to estimate how it extends and how thick it is. The weighted average of 25 such tomograms shows that it exists beneath the ARA and has its upper boundary at a depth of $5 \mathrm{~km}$. The 


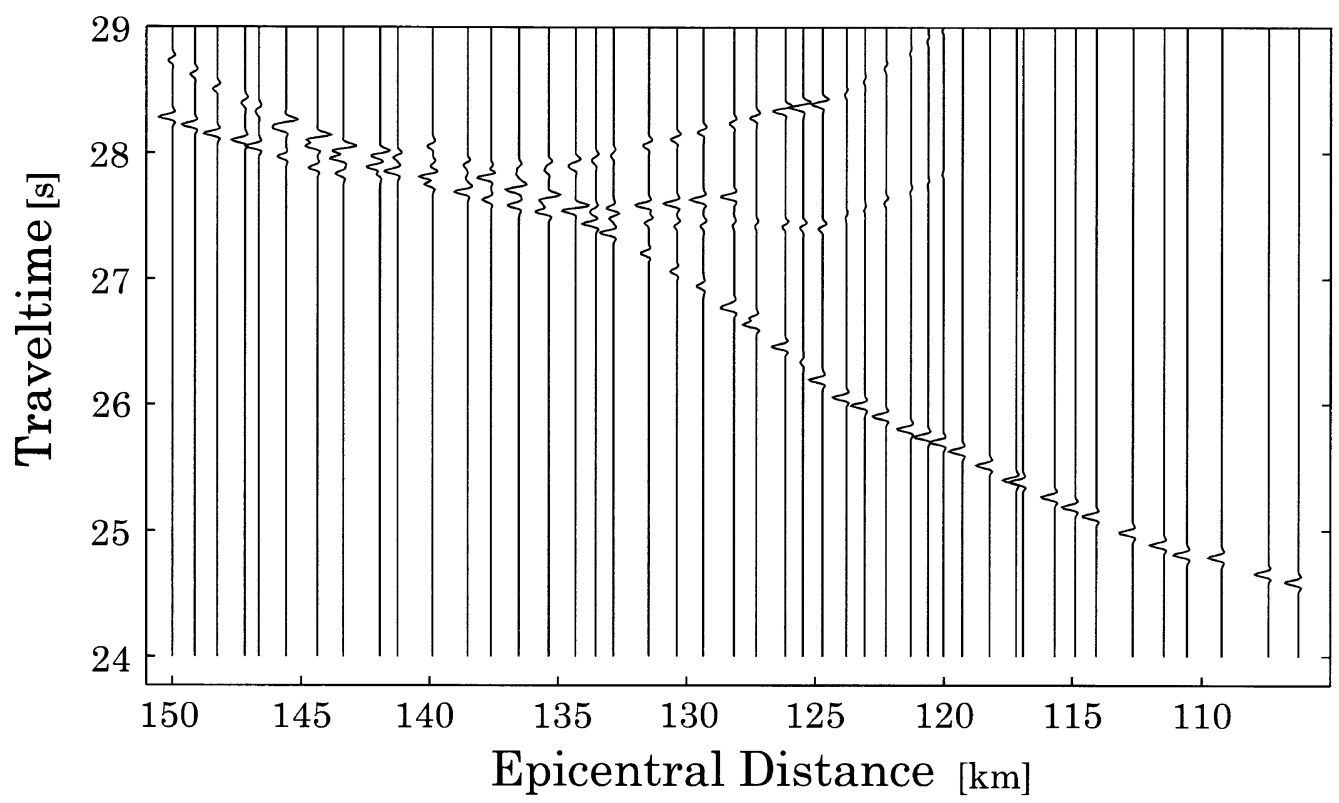

Fig. 10. Synthetic seismograms of $P$-wave for the model shown in Fig. 9. Amplitudes are normalized by the maximum amplitude of individual trace. The horizontal axis is an epicentral distance in $\mathrm{km}$. The source is located at $36.67^{\circ} \mathrm{N}, 139.06^{\circ} \mathrm{E}, 147.92 \mathrm{~km}$ deep. The vertical axis is a travel time in s.

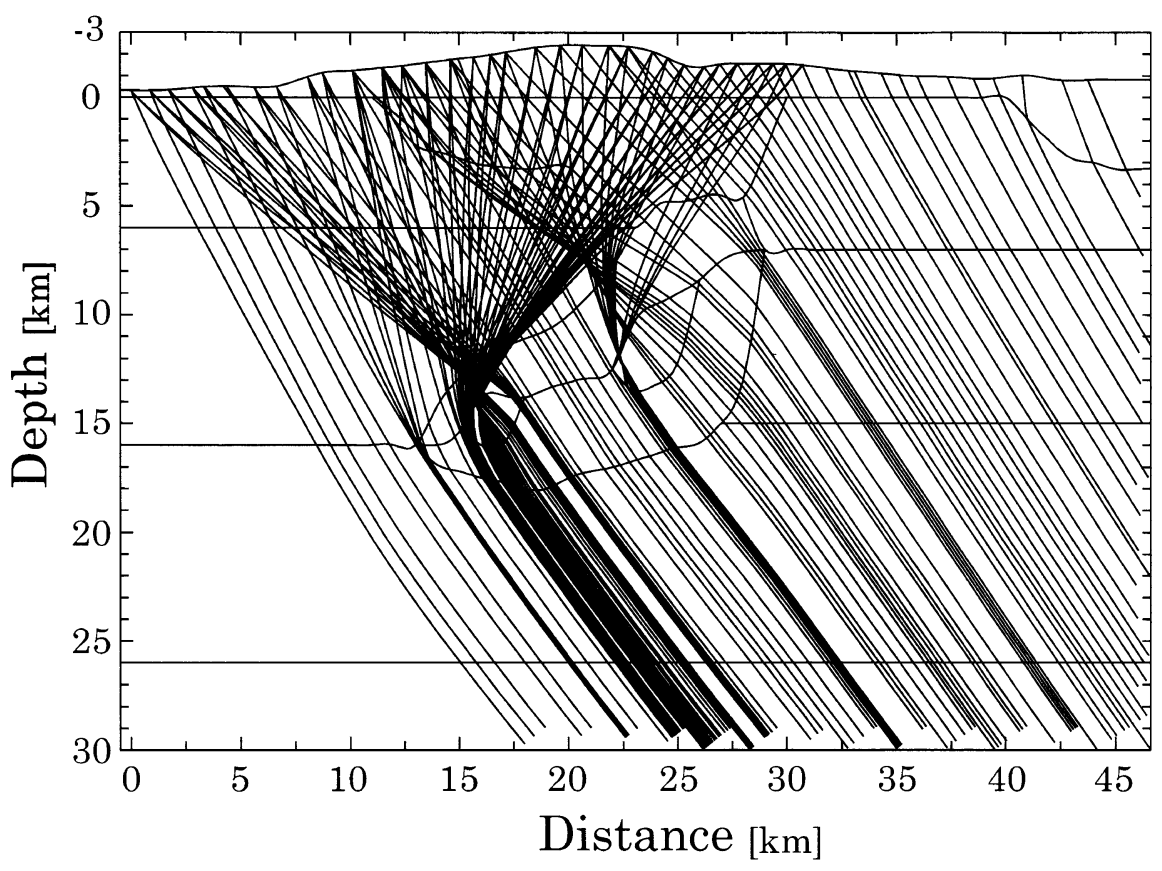

Fig. 11. Ray paths of P-wave for the model shown in Fig. 9. The source is located at $36.67^{\circ} \mathrm{N}, 139.06^{\circ} \mathrm{E}, 147.92 \mathrm{~km}$ deep. Receivers are located at the ARA array stations. The vertical axis is depth in $\mathrm{km}$ and the horizontal axis is distance from No. 45 to the east.

width of the low $V$ zone is $6 \pm 1 \mathrm{~km}$ from stations No. 17 to 24. Its lower boundary is located at a depth of $17 \pm 1 \mathrm{~km}$. The zone extends toward the west beneath station No. 35 . The lowest velocity of this zone obtained from travel time inversion is $4.92 \pm 0.05 \mathrm{~km} / \mathrm{s}$ at a depth of $11 \mathrm{~km}$ and a longitude of $137.645^{\circ} \mathrm{E}$. A true $V_{P}$ can be lower than that we obtained from the inversion due to poor resolution, as discussed in the resolution analysis. The forward modeling, which handles both first and later arrivals, constrains the $V_{P}$ to be $4.1 \mathrm{~km} / \mathrm{s}$.
There is a low $V_{S}$ zone at a depth of $13 \mathrm{~km}$ and a longitude of $137.623^{\circ} \mathrm{E}$ (Fig. 7). There is also a low $V_{S}$ at a depth of $15 \mathrm{~km}$ beneath stations No. 21 through 27 . The lowest $V_{S}$ is $2.54 \pm 0.12 \mathrm{~km} / \mathrm{s}$ at a depth of $13 \mathrm{~km}$ and a longitude of $137.623^{\circ} \mathrm{E}$. High $V_{S}$ zone is located at a depth of $5 \mathrm{~km}$ and a longitude around $137.65^{\circ} \mathrm{E}$ and low $V_{S}$ zone is located at a depth of $10 \mathrm{~km}$ and a longitude of $137.69^{\circ} \mathrm{E}$. Comparing the inverted $V_{P}$ and $V_{S}$, the $V_{P} / V_{S}$ ratio is $1.85 \pm 0.1$ in the low $V_{P}$ and low $V_{S}$ region.

Finally, the forward modeling indicates that the low $V_{P}$ is 

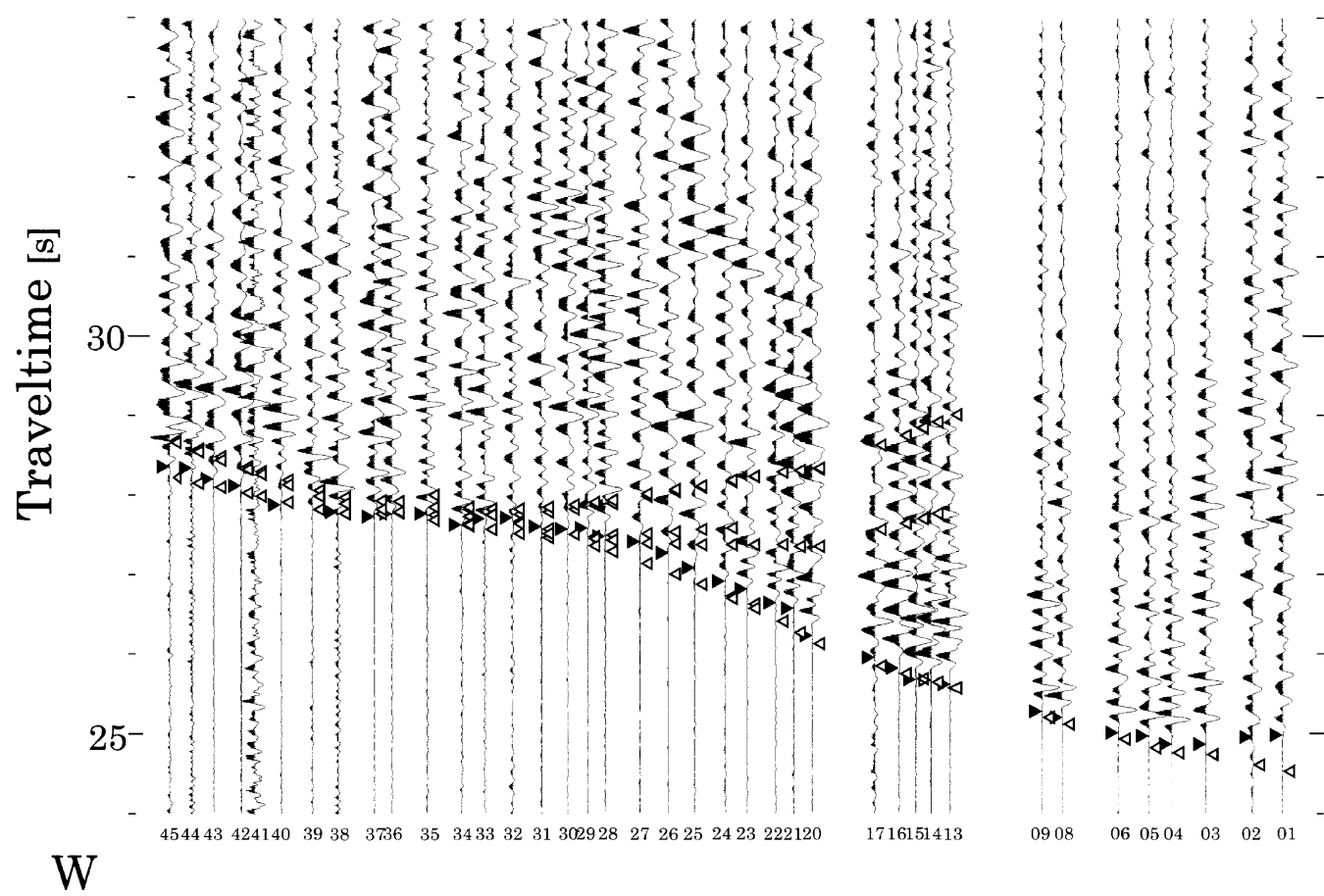

$\mathrm{E}$

Fig. 12. Observed seismograms of a vertical component for event No. $150\left(36.67^{\circ} \mathrm{N}, 139.06^{\circ} \mathrm{E}, 147.92 \mathrm{~km}\right.$ deep, $\left.\mathrm{M}=3.8\right)$. Solid triangles denote arrival times picked by eye. Open triangles denote arrival times calculated for the model shown in Fig. 9. Records are band-pass filtered (1-8 Hz). Amplitudes are normalized by the maximum amplitude of each trace. The vertical axis is a travel time. Each trace is plotted as an epicentral distance.

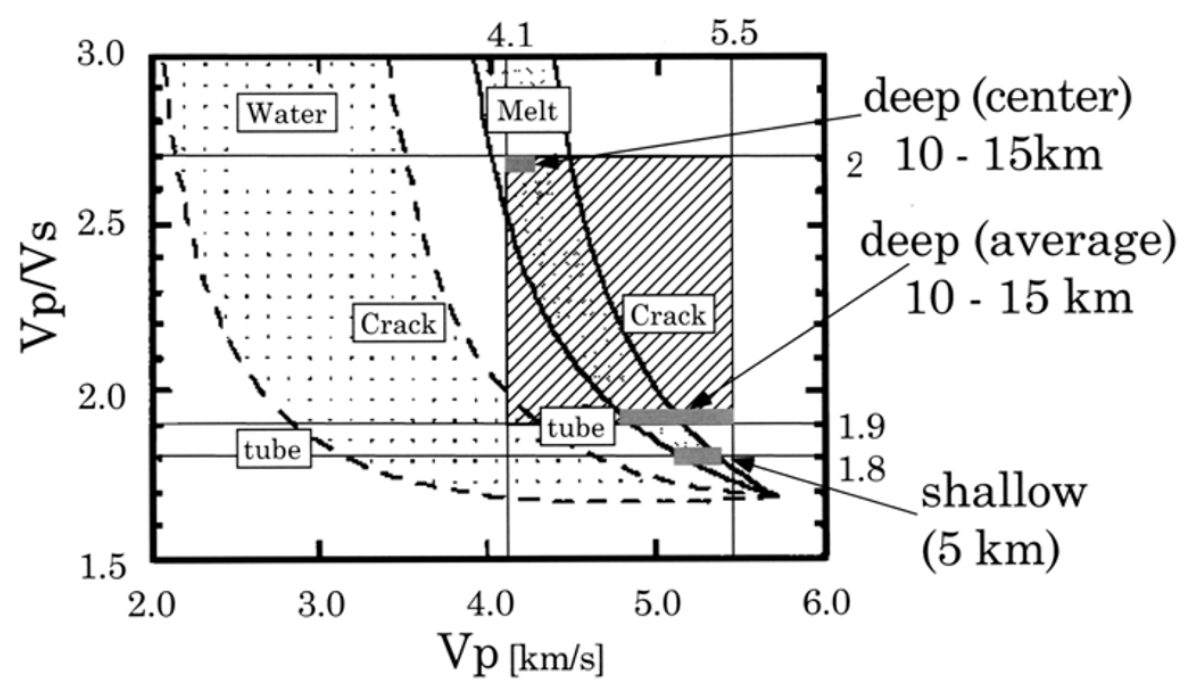

Fig. 13. Relationship between the velocity ratio $V_{P} / V_{S}$ and the $V_{P}$ calculated for rocks containing fluids in tube and crack shapes. The hatched rectangle is the region of the result of our study. (After Watanabe, 1994.)

$4.10 \mathrm{~km} / \mathrm{s}$ at a depth of $11 \mathrm{~km}$ and the low $V_{S}$ is $1.51 \mathrm{~km} / \mathrm{s}$ at the same place, where the $V_{P} / V_{S}$ is 2.70 .

\subsection{Comparison with the models of previous studies}

This study provides detailed information on low- $V$ areas. Hirahara et al. (1989) reported that a low- $V$ zone exists beneath the Hida Mountains from a tomographic inversion. Our results generally accord with theirs.

Sakai et al. (1996) found that an upward convex reflector exists at depths of 4-6 km. They assumed that the $V_{P}$ at depths of $0-4 \mathrm{~km}$ was $3.3 \mathrm{~km} / \mathrm{s}$. In our model, the $V_{P}$ at depths of $0-4 \mathrm{~km}$ is about $4.5 \mathrm{~km} / \mathrm{s}$ and $5.2-5.4 \mathrm{~km} / \mathrm{s}$ at depths of 4-6 km. The reflector may be shifted to a deeper position in our study than in theirs because the $V_{P}$ in our model is larger than that of their model. Their reflector corresponds to the upper boundary of the low velocity zone at $9 \mathrm{~km}$ depth in our study.

Katsumata et al. (1995) revealed a low- $V$ zone with a thickness of 1-2 km beneath Mt. Tateyama which explains the later phases of deep earthquakes. Our study showed that low- $V$ zones exist beneath Mt. Tateyama at depths of 0-3 $\mathrm{km}$ and $9-17 \mathrm{~km}$ from tomographic analysis and forward modeling. 


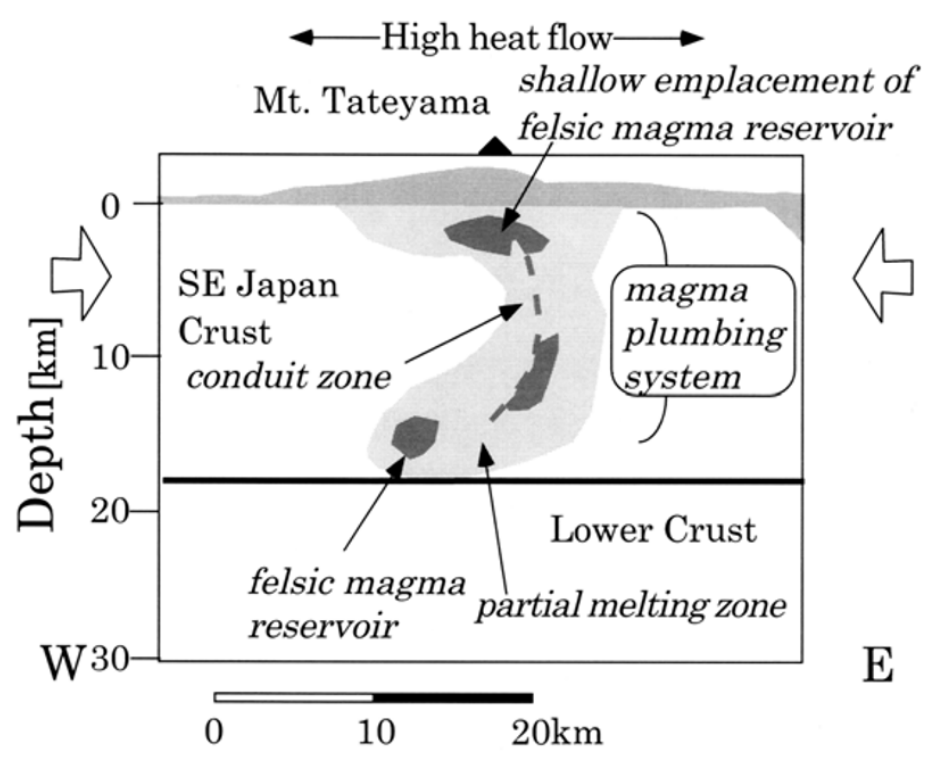

Fig. 14. Magma plumbing system beneath Mt. Tateyama.

In our study, because of the difficulty of handling site effects of the stations, we did not analyze quantitatively the amplitude of waves. Our data, however, show large amplitude variations with stations. For example, seismograms of the stations in the Kurobe tunnel, from stations No. 14 to 18 , and in the Kanden tunnel, No. 24, show small amplitudes. We consider that the attenuation of waves in the low velocity region is one of the reasons; however, the site effects may also affect the variation of the amplitude. We placed seismometers on the hard bedrock at each station in the tunnels. The amplitudes of waves through the low- $V$ zone would become smaller because waves spread there. Therefore, we need to analyze quantitatively site effects and geometrical spreading of velocity distribution to estimate the $\mathrm{Q}$ structure. This will be our future work.

\subsection{Existence of a partially molten rock in the low ve- locity area}

Seismic velocity in crustal rocks depends on many factors, such as mineral composition, temperature, pressure, crack density, and fluid content. Considering a high $V_{P} / V_{S}$ ratio such as 2.7 , the effect of fluid content is a candidate for the low velocity beneath Mt. Tateyama. The low $V_{P}$ and low $V_{S}$ can be associated with fluid-filled cracks or partially melting rocks. The degree of the effect on velocity reduction of $V_{P}$ and $V_{S}$ depends on the chemical composition of the fluid: aquareous or melt.

To resolve whether the fluid is melting rock or hot water, we use the $V_{P} / V_{S}$ ratio. According to Watanabe (1994), for a given $V_{P}$, the $V_{P} / V_{S}$ ratio with the partially melting rock is higher than that with the hot water. Figure 13 shows the relationship between the $V_{P}$ and the $V_{P} / V_{S}$ ratio. The $V_{P} / V_{S}$ ratio increases with the degree of fluid content. If the $V_{P}$ is between $5.0 \mathrm{~km} / \mathrm{s}$ and $5.5 \mathrm{~km} / \mathrm{s}$, the $V_{P} / V_{S}$ ratio with the hot water is between 1.7 and 1.75 , and that with the partially melting rock is between 1.75 and 1.85 . If the $V_{P}$ is between $4.1 \mathrm{~km} / \mathrm{s}$ and $4.5 \mathrm{~km} / \mathrm{s}$, the $V_{P} / V_{S}$ ratio with the hot water is between 1.7 and 1.95 , and that with the partially melting rock is higher than 2.1 . Low $V_{P}(4.1 \mathrm{~km} / \mathrm{s})$ and high
$V_{P} / V_{S}$ ratio (2.7) indicate the existence of a partially melting rock. The $V_{P} / V_{S}$ ratio (2.7) in a deep area at a depth of about $15 \mathrm{~km}$ is larger than that (1.8) in a shallow area at a depth of about $5 \mathrm{~km}$.

If there is partially melting rock, $15 \%$ of the fluid fraction with tube shape of a low velocity zone can explain the low $V_{P}$ of $4.1 \mathrm{~km} / \mathrm{s}$ and the high $V_{P} / V_{S}$ ratio of 2.7 , and $5 \%$ of the fluid fraction of a low velocity zone with tube shape can explain the low $V_{P}$ of $5.4 \mathrm{~km} / \mathrm{s}$ and the high $V_{P} / V_{S}$ ratio of 1.8 (Watanabe, 1994). The ratio of the partially melting rock in the deeper zone is larger than that in the shallower zone. These observations suggest that the low- $V$ zone is a magma reservoir or the region where magma is solidifying.

There are two low $V_{P}$ zones, at depths of $4 \mathrm{~km}$ and 15 $\mathrm{km}$. The deeper zone is located just above the upper/lower crustal boundary (Kimura and Yoshida, 1999). Geological and petrological studies indicate a multi-trap crustal magma plumbing system beneath the Norikura Volcanic Chain, in central Japan (Kimura and Yoshida, 1999). Their model suggests that at least four magma chambers at different depths exist to explain complex magma activities that occurred at Ontake volcano in the Late Pleistocene. Our tomographic image is consistent with their model: the low velocity zone at a depth of $4 \mathrm{~km}$ may be an uppermost emplacement of felsic magma. The $15-\mathrm{km}$-deep low- $V$ zone may correspond to a magma chamber in which felsic magma is segregated in the bottom part of the upper crust where a brittle-ductile transition may take place (Fig. 14). These magmas are supplied from deeper reservoirs in the lower crust and uppermost mantle (Zhao et al., 1992), which are not imaged by the present study.

\section{Conclusion}

We conducted a seismic observation in Chubu District in 1996 and deployed a dense array along the Tateyama-Kurobe Alpine Route to clarify detailed structure beneath the Hida Mountains. We recorded 412 earthquakes for 2 months, from which 54 earthquakes were selected for a tomographic study. 
$V_{P}$ and $V_{S}$ structures were estimated by a travel time inversion method. We used the checkerboard resolution test and numerical experiments to evaluate the method's reliability. We derived a structure model that can explain both first and later phases by forward modeling. A low velocity zone was found beneath the Hida Mountains at depths of $2-4 \mathrm{~km}$ and another was found at depths of $12-20 \mathrm{~km}$. The lowest $V_{P}$ is $4.1 \mathrm{~km} / \mathrm{s}$ and the lowest $V_{S}$ is $1.5 \mathrm{~km} / \mathrm{s}$. A high $V_{P} / V_{S}(2.7)$ ratio indicates that a partially melting rock exists beneath the Hida Mountains. The tomographic images suggest that the felsic magma partially melts at the bottom of the upper crust. We may have imaged the initial stage of felsic magma formation.

Acknowledgments. We are grateful to the participants of the Joint Seismic Observation in Chubu District in 1996. The observation was conducted by seven Japanese universities: Toyama Univ., Kanazawa Univ., Tohoku Univ., Chiba Univ., Hokkaido Univ., Hirosaki Univ., and the Earthquake Research Institute of the Univ. of Tokyo. We are especially thankful to Toshio Haneda, Shin'ichi Hashimoto, Masaru Kobayashi, and Kaname Sakai, the staff members in the Shin'etsu Earthquake Observatory of the Earthquake Research Institute, the University of Tokyo, for teaching one of the authors (M.M.) the technical details of observation. Yoshihiro Hiramatsu, Tooru Watanabe, and Yukio Fukahata helped us to install the RMA stations. We are also grateful to Dapeng Zhao for allowing us to use his tomography code and for his helpful advices for using the code. We used the program package SEIS83 as the asymptotic ray tracing for calculating the ray paths and travel times. Some of the figures were made using the Generic Mapping Tool (Wessel and Smith, 1991). This study was conducted under the Seventh National Program for Earthquake Prediction, and was partly supported by a Grant-in-Aid for Scientific Research (c) (2) from the Japanese Ministry of Education, Science, Sports and Culture (No. 10640400).

\section{References}

Campillo, M., B. Feignier, M. Bouchon, and N. Bethoux, Attenuation of crustal waves across the Alpine range, J. Geophys. Res., 98, 1987-1996, 1993.

Červený, V. and I. Psencik, Program package SEIS83, Charles Univ., Prague., 1983.

Fukao, Y. and K. Yamaoka, Stress estimate for the highest mountain system in Japan, Tectonics, 2(5), 453-471, 1983.

GROUPS96, The 1996 Joint Geophysical Research in the Hida district, Prog. Abs. seismo. Soc. Japan, 1996 (in Japanese).
Hirahara, K., A. Ikami, M. Ishida, and T. Mikumo, Three-dimensional Pwave velocity structure beneath Central Japan: low-velocity bodies in the wedge portion of the upper mantle above high-velocity subducting plates, Tectonophys., 163, 63-73. 1989.

Hirata, N. and M. Matsu'ura, Maximum-likelihood estimation of hypocenter with origin time eliminated using nonlinear inversion technique, Phys. Earth Planet. Inter., 47, 50-61, 1987.

Ikeda, Y., The fact of topographical observation about the form of the Hida Mountains, Chikyu Monthly, 18, 62-76, 1996 (in Japanese).

Katsumata, K., T. Urabe, and M. Mizoue, Evidence for a seismic attenuation anomaly beneath the Hida Mountain Range, Central Honshu, Japan, Geophys. J. Int., 120, 237-246, 1995.

Kimura, J. and T. Yoshida, Magma plumbing system beneath Ontake Volcano, central Japan, The Island Arc, 8, 1-29, 1999.

Mikumo, T., K. Hirahara, F. Takeuchi, H. Wada, T. Tsukuda, I. Fujii, and K. Nishigami, Three-dimensional velocity structure of the upper crust in the Hida Region, Central Honshu, Japan, and its relation to local seismicity, quaternary active volcanoes and faults, J. Phys. Earth, 43, 59-78, 1995.

Research Group for Explosion Seismology, Seismic refraction experiment in the Central Japan; Agatsuma-Kanazawa profile, Bull. Earthq. Res. Inst., 69, 139-158, 1994 (in Japanese with English abstract).

Ruzankin, A. I., I. L. Nersesov, and V. I. Khalturin, Propagation of $L_{g}$ and lateral variations in crustal structure in Asia, J. Geophys. Res., 82, 307-316, 1977.

Sakai, S., T. Iwasaki, T. Iidaka, T. Yoshii, F. Yamazaki, and T. Kuwayama, The structure of the crust of Chubu region from the explosion observation, Chikyu Monthly, 18, 104-108, 1996 (in Japanese).

Shinohara, M., N. Hirata, and S. Matsuda, Long-term low-power DAT seismic digital data recorder with GPS clock, Zisin, 50, 119-124, 1997 (in Japanese with English abstract).

Takeda, T., Reanalysis for seismic refraction data in Nagano Basin Area, Japan - crustal structure in Central Japan-, Master Thesis, Tokyo University, 1997 (in Japanese).

Urabe, T., A common format for multi-channel earthquake waveform data, Prog. Abs. seismo. Soc. Japan, 2, 384, 1994 (in Japanese).

Watanabe T., Melt beneath volcanoes-Inference from seismic velocitiesMem. Geol. Soc. Japan, 43, 20-31, 1994 (in Japanese with English abstract).

Wessel, P. and W. H. F. Smith, Free software helps map and display data, Eos Trans. $A G U, \mathbf{7 2}, 441,445-446,1991$.

Zhao, D. and A. Hasegawa, P wave tomographic imaging of the crust and upper mantle beneath the Japan islands, J. Geophys. Res., 98, 4533-4353, 1993.

Zhao, D., A. Hasegawa, and S. Horiuchi, Tomographic imaging of P and S wave velocity structure beneath Northeastern Japan, J. Geophys. Res., 97, 19909-19928, 1992.

M. Matsubara, (e-mail: mak@eri.u-tokyo.ac.jp), N. Hirata (e-mail: hirata@eri.u-tokyo.ac.jp), S. Sakai (e-mail: coco@eri.u-tokyo.ac.jp), and I. Kawasaki (e-mail: kawasaki@sci.toyama-u.ac.jp) 